\title{
Divacancies and the hydrogenation of Mg-Ti films with short range chemical order
}

\author{
H. Leegwater, ${ }^{1}$ H. Schut, ${ }^{1}$ W. Egger, ${ }^{2}$ A. Baldi, ${ }^{3}$ B. Dam, ${ }^{3}$ and S. W. H. Eijt ${ }^{1, a)}$ \\ ${ }^{1}$ Department of Radiation, Radionuclides and Reactors, Faculty of Applied Sciences, Delft University \\ of Technology, Mekelweg 15, NL-2629 JB Delft, The Netherlands \\ ${ }^{2}$ Institut für Angewandte Physik und Messtechnik, Universität der Bundeswehr München, \\ Werner-Heisenberg-Weg 39, D-85579 Neubiberg, Germany \\ ${ }^{3}$ Department of Chemical Engineering, Faculty of Applied Sciences, Delft University of Technology, \\ Julianalaan 136, NL-2628 BL Delft, The Netherlands
}

(Received 13 January 2010; accepted 1 March 2010; published online 22 March 2010)

\begin{abstract}
We obtained evidence for the partial chemical segregation of as-deposited and hydrogenated $\mathrm{Mg}_{1-\mathrm{y}} \mathrm{Ti}_{\mathrm{y}}$ films $(0 \leq \mathrm{y} \leq 0.30)$ into nanoscale $\mathrm{Ti}$ and $\mathrm{Mg}$ domains using positron Doppler-broadening. We exclusively monitor the hydrogenation of $\mathrm{Mg}$ domains, owing to the large difference in positron affinity for $\mathrm{Mg}$ and $\mathrm{Ti}$. The electron momentum distribution broadens significantly upon transformation to the $\mathrm{MgH}_{2}$ phase over the whole compositional range. This reveals the similarity of the metal-insulator transition for rutile and fluorite $\mathrm{MgH}_{2}$. Positron lifetime studies show the presence of divacancies in the as-deposited and hydrogenated Mg-Ti metal films. In conjunction with the relatively large local lattice relaxations we deduce to be present in fluorite $\mathrm{MgH}_{2}$, these may be responsible for the fast hydrogen sorption kinetics in this $\mathrm{MgH}_{2}$ phase. (C) 2010 American Institute of Physics. [doi:10.1063/1.3368698]
\end{abstract}

$\mathrm{Mg}$-Ti alloys are promising materials for application as hydrogen storage media, metal hydride rechargeable batteries, hydrogen sensors, and smart solar collectors. ${ }^{1,2}$ Hydrogenation of $\mathrm{Mg}$ - $\mathrm{Ti}$ films with Ti-concentrations larger than $\sim 15 \% \quad\left(\mathrm{Mg}_{0.85} \mathrm{Ti}_{0.15}\right)$ leads to the formation of a fluorite $\mathrm{Mg}_{1-\mathrm{y}} \mathrm{Ti}_{\mathrm{y}} \mathrm{H}_{\mathrm{x}}$ phase with substantially faster hydrogenation kinetics than the common rutile $\mathrm{MgH}_{2}$ phase. At the same time, a high hydrogen storage capacity of up to $6.5 \mathrm{wt} \%$ capacity is reached for $\mathrm{Mg}_{0.80} \mathrm{Ti}_{0.20}$.

The Mg-Ti(-H) films have an intriguing microstructure. While $\mathrm{Ti}$ and $\mathrm{Mg}$ are immiscible metals on a macroscopic scale, codeposition of $\mathrm{Mg}$ and $\mathrm{Ti}$ by magnetron sputtering leads to Mg-Ti films with a coherent structure, as indicated by $\mathrm{x}$-ray and electron diffraction studies, ${ }^{3-5}$ and a very high degree of intermixing of the Mg and Ti. Extended x-ray absorption fine structure (EXAFS) studies, in contrast, indicated that atomically mixed alloys are not formed. Instead, a partial chemical segregation into $\mathrm{Mg}$ and $\mathrm{Ti}$ domains on a length scale of the order of less than $10 \mathrm{~nm}$ was suggested. ${ }^{4}$ The stabilization of the cubic fluorite phase is thought to occur via elastic coupling of $\mathrm{MgH}_{2}$ to the nanoscale $\mathrm{TiH}_{2}$ domains. This coupling remains effective during the full (de)hydrogenation cycle because of the similarity of the unit cell volumes of cubic $\mathrm{TiH}_{2}$ and hexagonal closed packed $\mathrm{Mg}$ in the intermediate state. ${ }^{4}$ A direct observation of these phase segregated domains, however, is currently lacking.

Furthermore, the fast hydrogen kinetics of these types of films-especially in the cubic hydride phase formed at $\mathrm{Ti}$ concentrations larger than $15 \%$-is not well understood. The metal hydride lattice contracts upon increased incorporation of $\mathrm{Ti}$, leading to reduced space for hydrogen mobility. ${ }^{3,4} \mathrm{It}$ was suggested that the unoccupied octahedral positions in the fluorite $\mathrm{MgH}_{2}$ structure could aid the hydrogen mobility. ${ }^{6}$ $A b$ initio studies indicate that vacancies form a key factor in

${ }^{a)}$ Electronic mail: s.w.h.eijt@tudelft.nl. the hydrogen diffusion of both the rutile and fluorite $\mathrm{MgH}_{2}$ phases. $^{7-9}$ Further insight into the occurrence of vacancies and their possible role in the hydrogenation kinetics in $\mathrm{Mg}$ Ti-H films is thus strongly warranted.

In recent studies on $\mathrm{Mg}, \mathrm{Mg}_{2} \mathrm{Ni}$, and $\mathrm{Mg} / \mathrm{Si}$ films, positron annihilation emerged as a sensitive tool to monitor the hydrogenation and phase transitions in Mg-based metal films in a depth-resolved manner. ${ }^{10}$ Here, we provide direct evidence for chemical segregation in $\mathrm{Mg}$-Ti films using the positron Doppler broadening depth profiling method. Furthermore, our positron annihilation lifetime spectroscopy (PALS) study shows that divacancies are present in the metal sublattice. Such vacancies may aid to the fast hydrogen sorption kinetics associated with the cubic fluorite $\mathrm{MgH}_{2}$ phase.

Four $\mathrm{Mg}_{90} \mathrm{Ti}_{10}$, four $\mathrm{Mg}_{70} \mathrm{Ti}_{30}$, and two Ti films were deposited in a UHV system by rf magnetron cosputtering of $\mathrm{Mg}$ and $\mathrm{Ti}$ targets in argon atmosphere, on suprasil glass substrates. The films were covered with a $1-5 \mathrm{~nm}$ Pd capping layer to prevent oxidation and enhance hydrogen dissociation. Two samples of each composition were hydrogenated using a pressure of $90-100$ mbar at room temperature. In addition, a Pd-capped Mg-layer with a thickness of $\sim 1.3 \mu \mathrm{m}$ was deposited on a glass substrate by dc plasma sputtering. The positron Doppler broadening of annihilation radiation $(511 \mathrm{keV})$ was measured using positrons with a kinetic energy in the range of $0-25 \mathrm{keV}$. Momentum windows $|p|<3.0 \times 10^{-3} m_{\mathrm{o}} c$ and $8.2 \times 10^{-3} m_{\mathrm{o}} c<|p|<23.4$ $\times 10^{-3} m_{\mathrm{o}} c$ for $S$ and $W$, respectively, were used ${ }^{11}$ (see inset of Fig. 1). The $S$ parameter is a measure of annihilation with valence electrons, providing sensitivity to the electronic structure and the presence of vacancies, while $W$ is a measure for positron annihilation with semicore electrons, providing chemical sensitivity to the positron trapping site. ${ }^{11}$ PALS studies were performed using the pulsed low energy positron beam system (PLEPS). ${ }^{12}$ Positron lifetime spectra were collected at selected depths using positron implantation 


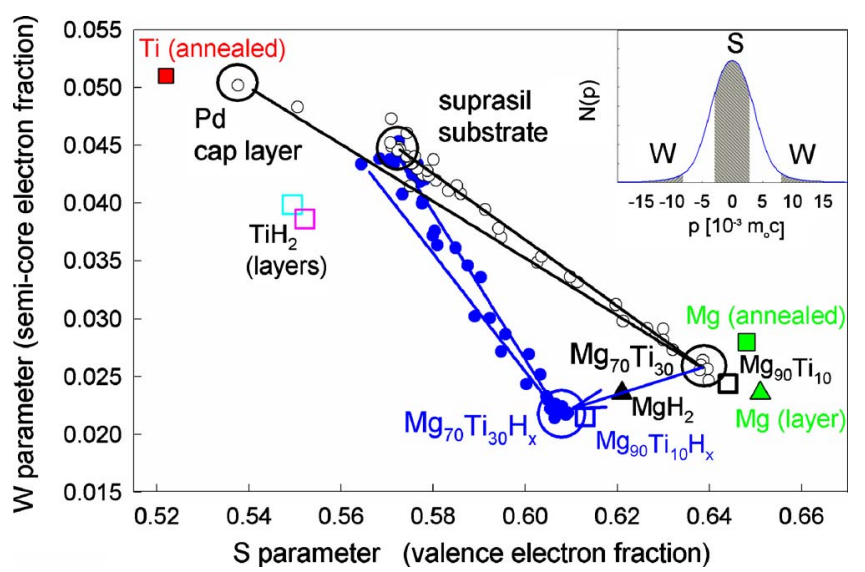

FIG. 1. (Color online) S-W diagram for as-deposited and hydrogenated $\mathrm{Mg}_{70} \mathrm{Ti}_{30}$ films, with the cluster points surrounded by circles; the running parameter is the positron implantation energy $E$. The solid lines are extracted from the combined VEPFIT analysis of the $\mathrm{S}$ and $\mathrm{W}$ depth profiles. For comparison purposes, the S-W cluster points are shown for (1) defect-free bulk Mg (Ref. 10) and Ti (filled squares), and (2) $\mathrm{Mg}$ (Ref. 10) and $\mathrm{MgH}_{2}$ (Ref. 10) films (filled triangles), $\mathrm{Mg}_{90} \mathrm{Ti}_{10}$ and $\mathrm{Mg}_{90} \mathrm{Ti}_{10} \mathrm{H}_{\mathrm{x}}$ films (open squares), and $\mathrm{TiH}_{2}$ (open squares) films.

energies in the range of $0.5-18 \mathrm{keV}$, and analyzed with POSWIN (Ref. 13) using a three lifetime component analysis. Reference spectra were collected on a $\mathrm{p}-\mathrm{SiC}$ reference sample to extract the instrumental time resolution function.

The results of the Doppler depth-profiling studies are summarized in the S-W diagram of Fig. 1. The depth-profiles were analyzed using the VEPFIT program; ${ }^{14}$ the fitted curves are characterized by straight lines in the $\mathrm{S}-\mathrm{W}$ diagram for as-deposited and for hydrogenated $\mathrm{Mg}_{70} \mathrm{Ti}_{30}$, reflecting the single layer behavior of the metal (metal hydride) layer. ${ }^{10}$ The S-W cluster point characteristic for the metal $\mathrm{Mg}_{70} \mathrm{Ti}_{30}$ phase shows a clear and large shift to the S-W point for the fluorite $\mathrm{Mg}_{70} \mathrm{Ti}_{30} \mathrm{H}_{\mathrm{x}}$ phase upon hydrogenation of the layer. Our previous studies ${ }^{10,15}$ demonstrated that such a large reduction in S-parameter is a direct result of the metalinsulator transition occurring during the transition from the $\mathrm{Mg}$ to the $\mathrm{MgH}_{2}$ phase. The transition from the free-electronlike $\mathrm{Mg}$ metal to the insulator metal hydride phase leads to a substantial broadening of the electron momentum distribution. $^{15}$

A remarkable feature of the $\mathrm{S}-\mathrm{W}$ diagram is that the cluster points for $\mathrm{Mg}_{70} \mathrm{Ti}_{30}$ and $\mathrm{Mg}_{90} \mathrm{Ti}_{10}$ lie very close to those of well-annealed (defect-free) $\mathrm{Mg}$ and of sputterdeposited Mg layers. ${ }^{10}$ Despite the high Ti-fractions of up to $30 \%$, the cluster points remain surprisingly far from the S-W point of well-annealed Ti. This is in a sharp contrast to $\mathrm{Mg}$ based alloys such as $\mathrm{Mg}_{2} \mathrm{Pd}$ and $\mathrm{Mg}_{2} \mathrm{Si}$, which show large shifts toward $\mathrm{S}-\mathrm{W}$ points intermediate of those of $\mathrm{Mg}$ and $\mathrm{Pd}$ or Si, respectively. ${ }^{10}$ Evidently, in our case, positrons do not see an Mg-Ti alloy with an atomically mixed composition but rather detect the presence of pure $\mathrm{Mg}$, as revealed from the position of the S-W cluster points. This selective detection requires the presence of chemically segregated $\mathrm{Mg}$ areas, into which the positron will trap during its diffusional motion which follows on the implantation and subsequent thermalization process. ${ }^{16}$ The trapping is driven by the large difference in positron affinity, by $2.1 \mathrm{eV},{ }^{17}$ for $\mathrm{Mg}$ metal relative to Ti (Fig. 2). The Ti domains embedded in a $\mathrm{Mg}$ environment will act as positronic potential barriers and, consequently, once a positron is injected in a Mg domain, it

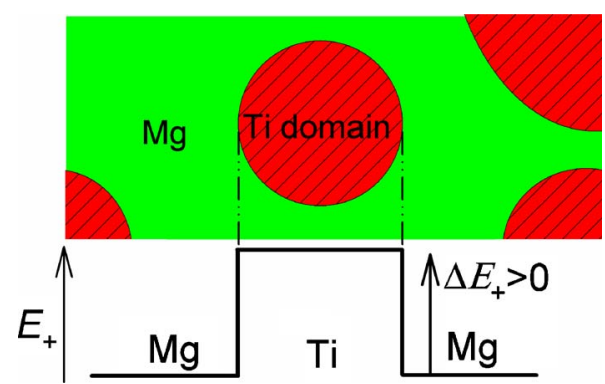

FIG. 2. (Color online) Schematic representation of the nanoscale chemically segregated $\mathrm{Mg}$-Ti domain structure. The schematic drawing for the positron potential energy $E_{+}$shows that a $\mathrm{Ti}$ domain embedded in $\mathrm{Mg}$ acts as a positronic potential barrier with height $\Delta E_{+}=2.1 \mathrm{eV}$ (Ref. 17).

will not be able to re-enter neighboring Ti domains during its diffusion motion. The positron Doppler broadening studies thus provide direct evidence for the presence of Mg domains that are chemically segregated from Ti domains. The absence of a clear signature of $\mathrm{Ti}$ in the positron measurements further indicates that the coherent embedding of Ti-domains in $\mathrm{Mg}$ leads to interfaces with hardly any vacancy-related defects. Such interface defects would act as positron trapping sites, which are easily detected by the positron method ${ }^{16,18}$ via annihilation with $3 d$-electrons of the surrounding Ti atoms since this would lead to a distinctly higher value of the W parameter than observed for Mg (Fig. 1).

The selective probing by positrons offers the interesting possibility to monitor the metal-insulator transformation of the $\mathrm{Mg}$ areas in these types of $\mathrm{Mg}$ - $\mathrm{Ti}$ films directly. Upon hydrogenation, the positrons remain confined to $\mathrm{MgH}_{2}$ areas, as demonstrated by the $\mathrm{S}-\mathrm{W}$ points of the $\mathrm{Mg}_{1-\mathrm{y}} \mathrm{Ti}_{\mathrm{y}} \mathrm{H}_{\mathrm{x}}$ metal hydrides which are localized close to the $\mathrm{S}-\mathrm{W}$ point of rutile $\mathrm{MgH}_{2}$, and far from that of $\mathrm{TiH}_{2}$ (Fig. 1). Figure 3 shows that the reduction in S-parameter upon hydrogenation of $\mathrm{Mg}$ - $\mathrm{Ti}$ films is nearly equally large for all three Ticompositions. This strongly indicates that the metal-toinsulator transition for the $\mathrm{Mg}$ domains is quite similar for either the formation of rutile or fluorite phase $\mathrm{MgH}_{2}$. This is quite remarkable given the complex overall optical and electronic properties observed in these nanoscale intermixed metal hydride films. ${ }^{2,5} \mathrm{Ab}$ initio modeling of the optical properties of these types of films so far concentrated on the atomically intermixed $\mathrm{Mg}_{0.75} \mathrm{Ti}_{0.25} \mathrm{H}_{2}$ alloy, which was found to be a metal. ${ }^{19}$

Finally, the PALS studies showed that saturation trapping and annihilation in vacancy-related defects occurs inside the $\mathrm{Mg}$ areas of the $\mathrm{Mg}-\mathrm{Ti}(-\mathrm{H})$ films. POSWIN analysis of the positron lifetime spectra at the specific implantation en-

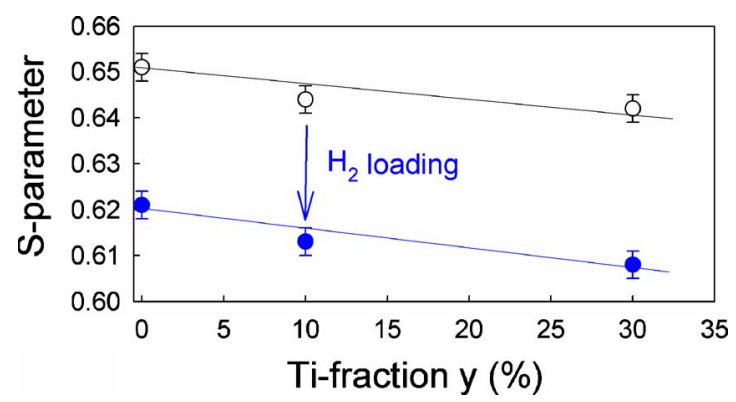

FIG. 3. (Color online) Doppler S-parameter for the $\mathrm{Mg}_{1-\mathrm{y}} \mathrm{Ti}_{\mathrm{y}}$ layers in the as-deposited (open circles) and hydrogenated (filled circles) states as a function of Ti-composition. 


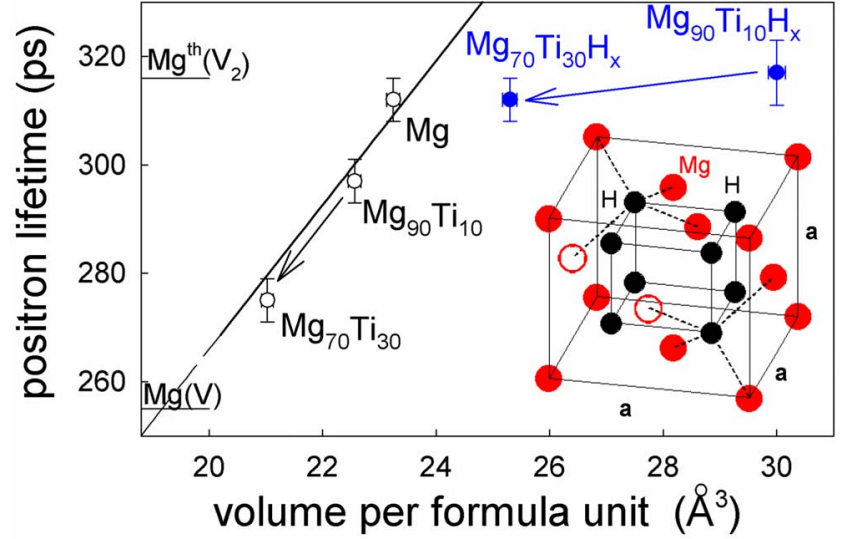

FIG. 4. (Color online) Positron lifetime $\tau$ of metallic and hydrogenated $\mathrm{Mg}_{1-\mathrm{y}} \mathrm{Ti}_{\mathrm{y}}$ films as a function of volume per formula unit $\mathrm{V}$. The solid line is a fit according to $\tau(\mathrm{ps})=13.3 \mathrm{~V}\left(\AA^{3}\right)$. For comparison, the experimental positron lifetime for the monovacancy (Ref. 22) and the theoretical positron lifetime for the divacancy (Ref. 21) in Mg are shown. The inset illustrates the (unrelaxed) geometry of the divacancy in the metal sublattice of fluorite phase $\mathrm{MgH}_{2}$.

ergies for which positrons annihilate solely within the $\mathrm{Mg}$ $\mathrm{Ti}(-\mathrm{H})$ layer, namely, revealed a nearly single exponential decay with a high intensity in the range $95 \%-100 \%$ for the second lifetime component, associated with vacancies, for each of these films. This shows that the defect concentrations are at least of the order of $10^{-4}$ (Ref. 20) but higher values are quite likely. Figure 4 presents the extracted positron lifetimes for the Mg layer, and for the Mg-Ti layers in the asdeposited and hydrogenated states. The measured positron lifetime of $312 \pm 4 \mathrm{ps}$ for the $\mathrm{Mg}$ film is close to the value of 316 ps for the divacancy in $\mathrm{Mg}$ obtained in recent $a b$ initio calculations. ${ }^{21}$ The comparison with experimental and theoretical positron lifetimes for the monovacancy ${ }^{22,23}$ and divacancy ${ }^{21}$ in $\mathrm{Mg}$ strongly indicates that trapping occurs in divacancies. Clearly, the detected positron lifetime in the $\mathrm{Mg}_{1-\mathrm{y}} \mathrm{Ti}_{\mathrm{y}}$ metal phase scales proportional to the volume per metal atom ${ }^{3,4}$ (Fig. 4), as expected for the divacancy. ${ }^{24}$ The $\mathrm{Mg}$-Ti lattice contracts proportionally to the Ti-fraction, ${ }^{3,4}$ which reduces the size of the divacancy. This leads to a larger electron density present at the positron trapping site with correspondingly higher positron annihilation rates. In contrast, Fig. 4 shows that the positron lifetime for fluorite phase $\mathrm{Mg}_{70} \mathrm{Ti}_{30} \mathrm{H}_{\mathrm{x}}$ is nearly equal to the positron lifetime for rutile phase $\mathrm{Mg}_{90} \mathrm{Ti}_{10} \mathrm{H}_{\mathrm{x}}$, despite the significantly smaller volume per formula unit, by $16 \%$, for the fluorite phase. ${ }^{3,4}$ This indicates that the divacancy in the fluorite $\mathrm{MgH}_{2}$ structure (inset of Fig. 4) occupies a relatively large open space leading to a low electron density. This requires local lattice relaxations of nearby hydrogen and $\mathrm{Mg}$ atoms, which can be facilitated by displacements to neighboring empty octahedral sites. ${ }^{6}$ The combined effect of divacancies present and relatively large local lattice relaxations may effectively lower the migration barriers for hydrogen diffusion in the fluorite $\mathrm{MgH}_{2}$ phase, leading to the fast hydrogen transport. Indeed, recent $a b$ initio modeling studies ${ }^{7-9}$ point to the relevance of vacancy-mediated hydrogen diffusion in $\mathrm{MgH}_{2}$ and related metal hydrides, since this provides a major contribution to the hydrogen mobility.

In conclusion, evidence for chemical segregation in $\mathrm{Mg}$-Ti films into $\mathrm{Mg}$ and $\mathrm{Ti}$ domains was obtained using positron annihilation methods. Selective detection of the $\mathrm{Mg}$ areas in these films provide a local view on the metal-toinsulator transition upon hydrogenation to fluorite phase $\mathrm{MgH}_{2}$. Experimental evidence is provided for the presence of divacancies in the metal sublattice of both the rutile and fluorite $\mathrm{MgH}_{2}$ phases. The lifetimes of these vacancies are comparable, though their size must differ considerably. Hence, we deduce the existence of local lattice relaxations in the fluorite phase, which may play a crucial role in the enhanced hydrogen transport in fluorite $\mathrm{MgH}_{2}$.

We thank H. Schreuders for preparation of the samples. The authors acknowledge the staff of NEPOMUC at FRM-II for assistance during the PLEPS experiments. This project was supported by the European Commission under the 7th Framework Programme, Key Action: Strengthening the European Research Area, Research Infrastructures, Contract No. 226507 (NMI3). The work at the Department of Chemical Engineering was supported by the Nederlandse Organisatie voor Wetenschappelijk Onderzoek (NWO) through the Sustainable Hydrogen Programme of ACTS.

${ }^{1}$ R. A. H. Niessen and P. H. L. Notten, Electrochem. Solid-State Lett. 8, A534 (2005).

${ }^{2}$ D. M. Borsa, R. Gremaud, A. Baldi, H. Schreuders, B. Dam, R. Griessen, P. Vermeulen, and P. H. L. Notten, Appl. Phys. Lett. 88, 241910 (2006).

${ }^{3}$ P. Vermeulen, P. C. J. Graat, H. J. Wondergem, and P. H. L. Notten, Int. J. Hydrogen Energy 33, 5646 (2008)

${ }^{4}$ A. Baldi, R. Gremaud, D. M. Borsa, C. P. Baldé, A. M. J. van der Eerden, G. L. Kruijtzer, P. E. de Jongh, B. Dam, and R. Griessen, Int. J. Hydrogen Energy 34, 1450 (2009).

${ }^{5}$ D. M. Borsa, R. Gremaud, A. Baldi, H. Schreuders, J. H. Rector, B. Kooi, P. Vermeulen, P. H. L. Notten, B. Dam, and R. Griessen, Phys. Rev. B 75 205408 (2007).

${ }^{6}$ W. P. Kalisvaart, P. Vermeulen, A. V. Ledovskikh, D. Danilov, and P. H. L. Notten, J. Alloys Compd. 446-447, 648 (2007).

${ }^{7}$ S. Hao and D. S. Sholl, Appl. Phys. Lett. 93, 251901 (2008).

${ }^{8}$ M. S. Park, A. Janotti, and C. G. van de Walle, Phys. Rev. B 80, 064102 (2009).

${ }^{9}$ S. Er, D. Tiwari, G. A. de Wijs, and G. Brocks, Phys. Rev. B 79, 024105 (2009).

${ }^{10}$ S. W. H. Eijt, R. Kind, S. Singh, H. Schut, W. J. Legerstee, R. W. A Hendrikx, V. L. Svetchnikov, R. J. Westerwaal, and B. Dam, J. Appl. Phys. 105, 043514 (2009).

${ }^{11}$ A. van Veen, H. Schut, and P. E. Mijnarends, in Positron Beams and Their Applications, edited by P. G. Coleman (World Scientific, Singapore, 2000), Chap. 6.

${ }^{12}$ W. Egger, P. Sperr, G. Kögel, and G. Dollinger, Phys. Status Solidi C 4, 3969 (2007).

${ }^{13}$ D. Bochert, Diploma thesis, Universität der Bundeswehr München, 2004.

${ }^{14}$ A. van Veen, H. Schut, J. de Vries, R. A. Hakvoort, and M. R. IJpma, AIP Conf. Proc. 218, 171 (1990).

${ }^{15}$ S. W. H. Eijt, Phys. Status Solidi C 6, 2561 (2009).

${ }^{16}$ S. W. H. Eijt, B. Barbiellini, A. J. Houtepen, D. Vanmaekelbergh, P. E. Mijnarends, and A. Bansil, Phys. Status Solidi C 4, 3883 (2007).

${ }^{17}$ R. Nieminen, in Positron Spectroscopy of Solids, Proceedings of the International School of Physics "Enrico Fermi" Vol. CXXV, edited by A. Dupasquier and A. P. Mills, Jr. (IOS, Amsterdam, 1995), p. 479.

${ }^{18}$ C. V. Falub, P. E. Mijnarends, S. W. H. Eijt, M. A. van Huis, A. van Veen, and H. Schut, Phys. Rev. B 66, 075426 (2002).

${ }^{19}$ M. J. van Setten, S. Er, G. Brocks, R. A. de Groot, and G. A. de Wijs, Phys. Rev. B 79, 125117 (2009).

${ }^{20} \mathrm{R}$. Krause-Rehberg and H. Leipner, Positron Annihilation in Semiconductors: Defect Studies (Springer, Berlin, 1999).

${ }^{21}$ J. M. Campillo Robles, private communication (February 18, 2010).

${ }^{22}$ P. Hautojärvi, J. Johansson, A. Vehanen, J. Yli-Kauppila, J. Hillairet, and P. Tzanétakis, Appl. Phys. A: Mater. Sci. Process. 27, 49 (1982).

${ }^{23}$ I. Makkonen and M. J. Puska, Phys. Rev. B 76, 054119 (2007).

${ }^{24}$ F. Plazaola, A. P. Seitsonen, and M. J. Puska, J. Phys.: Condens. Matter 6, 8809 (1994). 